\title{
Artefatos de Couro de Ipirá: potencial de Indicação Geográfica no território da Bacia do Jacuípe - Bahia
}

\author{
Ipirá Leather Artifacts: Geographical Indication potential in the Jacuipe \\ Bay Territory - Bahia
}

\author{
Bartolomeu das Neves Marques ${ }^{1}$ \\ Camila Santos Bulcão ${ }^{1}$ \\ Ângela Maria Ferreira Lima ${ }^{1}$ \\ Jerisnaldo Matos Lopes ${ }^{1}$ \\ Marcelo Santana Silva ${ }^{1}$ \\ ${ }^{1}$ Instituto Federal da Bahia, Salvador, BA, Brasil
}

\begin{abstract}
Resumo
Este trabalho tem como objetivos identificar e apresentar as características que o município de Ipirá reúne para um registro de Indicação Geográfica (IG), na forma de Indicação de Procedência (IP), dos seus artefatos de couro, considerando os aspectos históricos e econômicos associados a essa produção. A metodologia adotou uma abordagem qualitativa, com pesquisa bibliográfica e consultas a sites especializados como fontes secundárias. O saber-fazer é uma característica singular e expressiva na localidade, que a distingue da produção de outros territórios e representa um potencial para a sua certificação junto ao Instituto Nacional da Propriedade Industrial, a partir da estruturação da cadeia produtiva com estabelecimento de governança para organização dos produtores e demais stakeholders. Concluiu-se que a produção de artefatos de couro de Ipirá tem grande potencial para Indicação Geográfica na modalidade de Indicação de Procedência (IP), podendo gerar benefícios que vão além da melhoria das condições econômicas da população.
\end{abstract}

Palavras-chave: Artefatos de Couro. Indicação Geográfica. Ipirá.

\begin{abstract}
This work aimed to identify and present the characteristics that the municipality of Ipirá gathers for a Geographical Indication (GI) record, in the form of Indication of Origin (IP), of its leather artifacts, considering the historical and economic aspects associated with this production. The methodology adopted a qualitative approach, with bibliographical research and queries to sites specialized as secondary sources. The know-how is a singular and expressive characteristic in the locality, which distinguishes it from the production of other territories and represents a potential for its certification with the National Institute of Industrial Property, from the structuring of the productive chain with establishment of governance for organization producers and other stakeholders. It was concluded that the production of leather artifacts of Ipira has great potential for Geographical Indication in the Indication of Origin (IP) mode, which can generate benefits that go beyond the improvement of the population's economic conditions.
\end{abstract}

Keywords: Leather Articles. Geographical Indication. Ipirá.

Área Tecnológica: Propriedade Intelectual. Indicação Geográfica. 


\section{Introdução}

A Indicação Geográfica (IG) representa a propriedade intelectual coletiva com a sua proteção e estabelece uma direta ligação entre as qualidades e características do produto e sua localização de origem e é comumente emitida por um escritório nacional de propriedade intelectual (NEILSON; WRIGHT; AKLIMAWATI, 2018). No Brasil, o Instituto Nacional da Propriedade Industrial (INPI) é o órgão responsável por estabelecer as condições de registro das Indicações Geográficas, conforme previsão da Lei Federal n. 9.279/96 (BRASIL, 1996).

Essa lei, assim como a Instrução Normativa n. 095/2018 do INPI (2018a), subdivide a IG como Indicação de Procedência (IP) e Denominação de Origem (DO), sendo considerada IP, em seu artigo 177 e artigo $2^{\circ}$, respectivamente, "[...] o nome geográfico de país, cidade, região ou localidade de seu território que se tenha tornado conhecido como centro de extração, produção ou fabricação de determinado produto ou de prestação de determinado serviço" (BRASIL, 1996, art. 117). Para este artigo, considera-se a IP mais adequada por se direcionar à produção ou fabricação dos artefatos de couro de Ipirá.

Presencia-se junto com o crescimento da oferta de novos produtos e serviços o surgimento, também, de novos nichos de mercado e a necessidade de novas estratégias de valorização do produto, sendo a IG uma das formas de conferir ao produto um diferencial competitivo (VIEIRA et al., 2014).

Todavia, apesar de na prática a relação entre alguns produtos e a sua origem não ser nova, a sua proteção como propriedade coletiva é relativamente recente, especialmente considerando que no Brasil o instrumento normativo mais representativo é a Lei de Propriedade Industrial, de 14 de maio de 1996. Por isso, são importantes a difusão de seus benefícios e o fortalecimento de cadeias produtivas com conhecimento e organização necessárias para se estruturarem como polos de oferecimento de produtos com qualidade tecnicamente comprovadas.

Diante do conhecimento acerca dos benefícios para o desenvolvimento de uma região a partir da Indicação Geográfica, surgiu como problema norteador de pesquisa o potencial que pode ser estruturado em uma localidade com a aplicação sistematizada de métodos de produção e organização. Nesse particular, o principal ativo a ser utilizado é o saber-fazer da comunidade, de modo que se fortaleça o sentimento de pertencimento ao sistema produtivo, gere reconhecimento dos membros de toda a cadeia produtiva e possibilidades reais de desenvolvimento econômico.

Como objetivo principal, buscou-se identificar e apresentar as características que o município de Ipirá no estado da Bahia reúne para o direcionamento a um registro de IG dos seus artefatos de couro, considerando todos os aspectos históricos e econômicos associados a essa produção.

Ipirá se diferencia pela produção de artefatos de couro, sendo a mão de obra local utilizada por algumas fábricas instaladas no município como a Dominus Acessórios em Couro, Classe Couro e a Aine Courum Loja da Fábrica, inclusive para acabamentos artesanais. A produção artesanal de artefatos, também, se mantém presente e reúne apropriações históricas do saber-fazer que confere aos produtos uma qualidade particular e de reconhecimento em outras regiões do país. A matéria-prima utilizada é, principalmente, trazida das regiões sudeste e sul, dada a qualidade do acabamento. 


\section{Metodologia}

Este trabalho foi estruturado a partir da operacionalização do objetivo geral, em uma abordagem qualitativa, com base em pesquisas bibliográficas acerca de Indicações Geográficas (IG), desenvolvimento territorial e cadeia produtiva do couro, como fundamentação para reconhecer e explicar a potencialidade de IG para a produção de artefatos de couro de Ipirá. Além de utilizar fontes secundárias como sites oficiais do Instituto Brasileiro de Geografia e Estatística (IBGE), Serviço Brasileiro de Apoio às Micro e Pequenas Empresas (SEBRAE), Instituto Nacional da Propriedade Industrial (INPI), leis, artigos e outros estudos acerca do tema.

A pesquisa está delimitada ao município de Ipirá, o qual está situado no território de identidade da Bacia do Jacuípe, conforme recorte do mapa do estado da Bahia (Figura 1), dividido por territórios de identidades, extraído do site oficial da Superintendência de Estudos Econômicos e Sociais da Bahia (SEI).

Figura 1 - Município de Ipirá

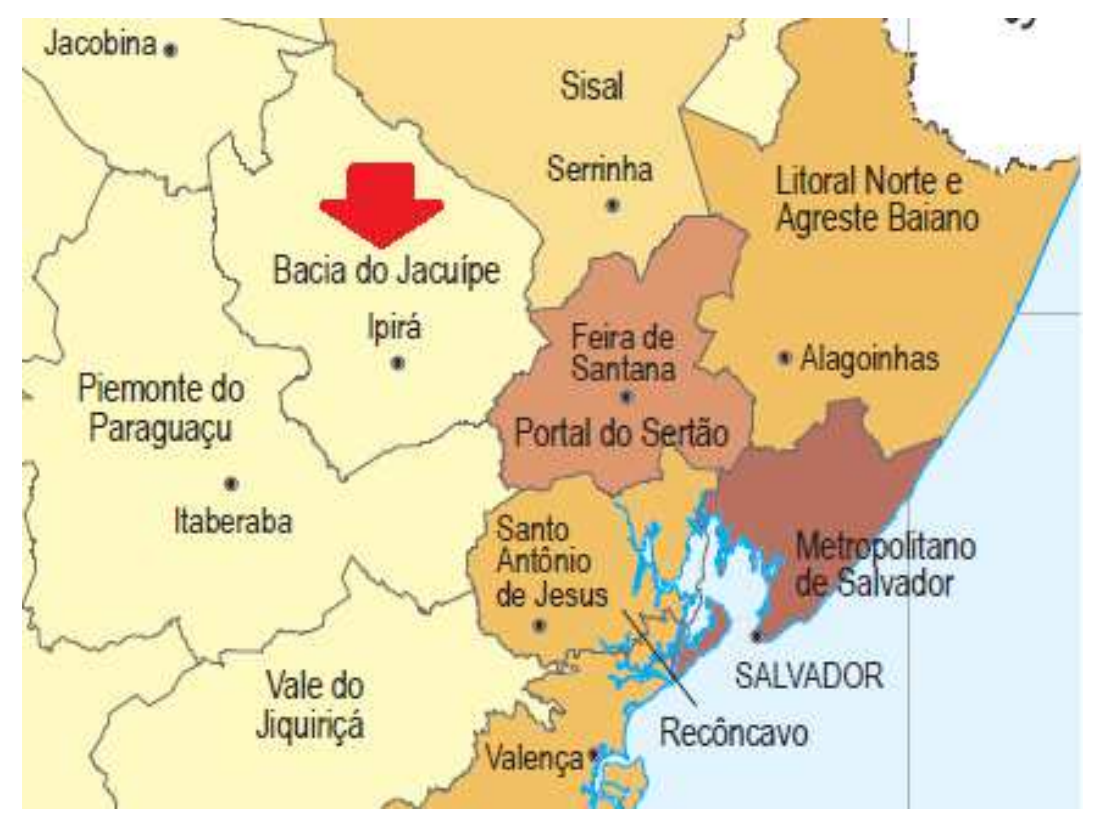

Fonte: Adaptada de SEI (2013)

Segundo o IBGE (2019), em 2017, estimou-se uma área territorial de 3.105,280 m², em 2018, a população estimada foi contabilizada em 59.763 pessoas, sendo 29.076 homens e 30.267 de mulheres, 29.009 na área urbana e 30.334 na área rural, em 2010 a densidade demográfica 19,39 hab/ $\mathrm{km}^{2}$, o PIB per capita levantado em 2016 foi de R\$ 11.054,26; o Índice de Desenvolvimento Humano do Município (IDHM) é de 0,549 e seu índice GINI é de 0,39. As coordenadas do município são longitude oeste - $39^{\circ} 44^{\prime} 14^{\prime \prime}$ e latitude sul - $12^{\circ} 09^{\prime} 30^{\prime \prime}$. Seus limites estão situados ao norte com os municípios de Pintadas e Pé de Serra, ao leste com Rafael Jambeiro, ao sul com Iaçu e a oeste com Itaberaba, Ruy Barbosa, Macajuba e Baixa Grande. Seu território está situado na região semiárida do nordeste do país, que abrange também todo sertão baiano (IPIRÁ, 2019). 


\section{O Mercado do Couro: do global ao local}

No mundo, o couro participa de diferentes cadeias produtivas e é dependente da pecuária de corte e dos frigoríficos, que são os geradores da principal matéria-prima e fornece insumos para diferentes cadeias produtivas: calçados e artefatos, vestuário, móveis e automobilística. Os curtumes são os principais componentes da indústria. Esses curtumes fornecem o couro em diferentes estágios: o couro salgado (mais simples e de menor valor agregado), o wet blue (tom azulado após processo de banho e remoção de graxas e gorduras), o crust (produto já seco e semiacabado) ou o couro acabado (maior valor agregado e possível de aplicação direta à produção) (ABDI, 2011).

No Brasil, a principal destinação do couro é para a indústria calçadista, de tradição no país e de importância para a economia nacional. O setor de calçados é compreendido por quatro segmentos de indústrias: calçados (couro e materiais sintéticos); artefatos de couro (bolsas, pastas, cintos etc.); curtume; componentes para artefatos e calçados (SEBRAE/BA, 2017).

A Bahia é um dos principais centros produtivos de couro do Brasil e fica atrás do Ceará e Paraíba na Região Nordeste, que é a maior produtora de calçados do país, responsável por $58 \%$ da produção nacional. Mas, os números demonstram a importância do couro para a indústria local, além de ser possível o aproveitamento de oportunidades de mercado para o crescimento, a exemplo do e-commerce (SEBRAE/BA, 2017).

O estudo de mercado realizado pelo SEBRAE revelou o panorama do setor de calçados na Bahia em 2015: o estado responde por mais de US\$ 48 milhões da exportação e faturamento estimado em quase $\mathrm{R} \$ 3$ bilhões; o volume médio exportado é de 3 milhões de pares de calçados/ano, considerando os últimos cinco anos pesquisados. $\mathrm{O}$ setor está geograficamente distribuído em 50 municípios baianos, representado por mais de 200 empresas e cerca de 28 mil pessoas empregadas. A produção de calçados de couro figura como a terceira no ranking nacional, com 19,7\%, revelando potencial de crescimento para a utilização do couro como matéria-prima para essa indústria (SEBRAE/BA, 2017).

\subsection{Cadeia Produtiva do Couro Bovino}

A cadeia produtiva seja a do couro e de outros setores é um termo genérico que identifica o conjunto de atividades de um setor industrial, a exemplo da indústria de calçados, automobilística, computadores e outros. Em resumo, a referência é sempre o termo cadeia produtiva seguida pelo nome do setor industrial de referência. A cadeia produtiva não se confunde com a cadeia de suprimentos, pois a segunda pode fazer parte de uma ou de várias cadeias produtivas, a qual envolve a movimentação de bens desde o estágio da matéria-prima até o usuário final (PIRES, 2016). 
Figura 2 - Cadeia Produtiva do Couro

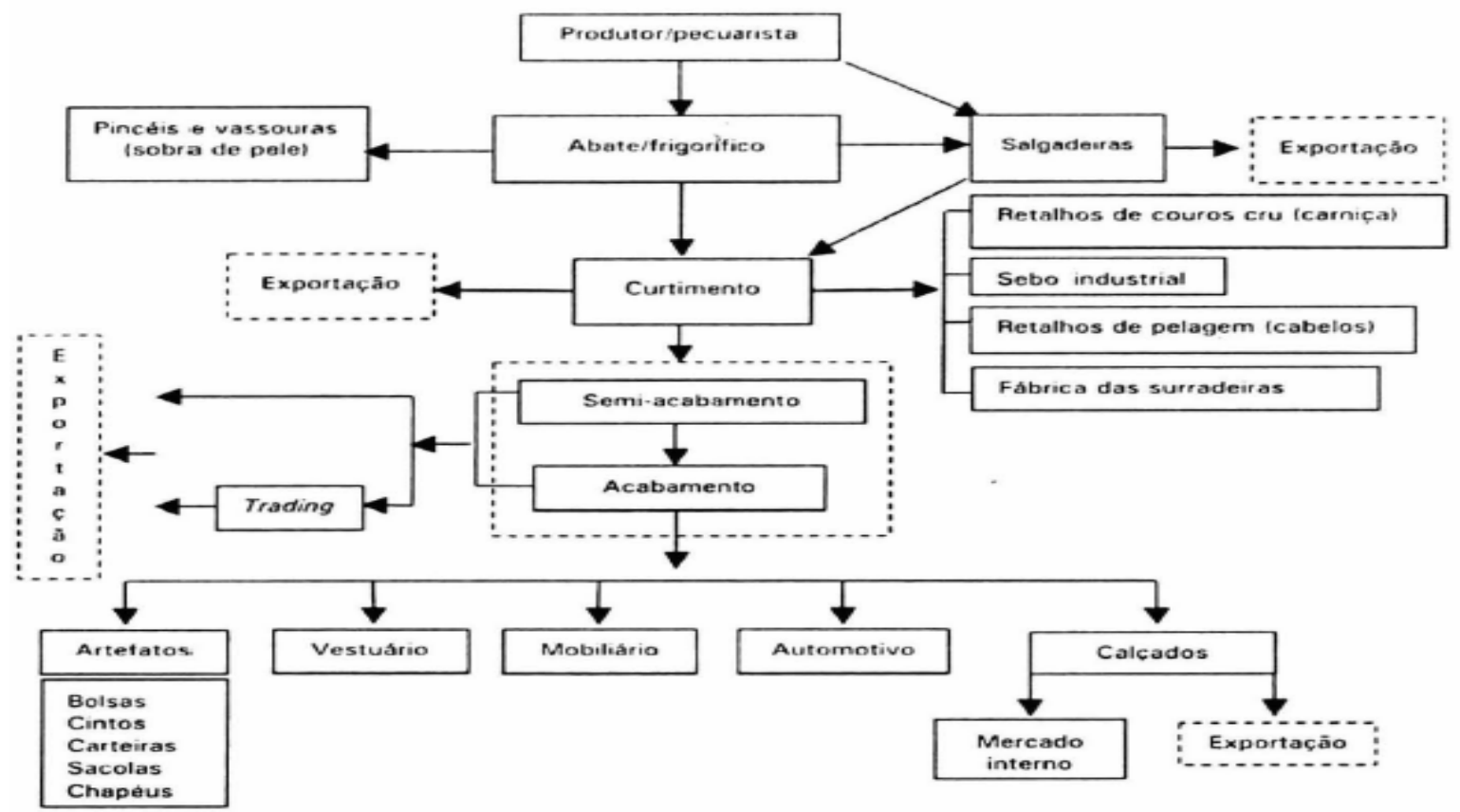

Fonte: EMBRAPA (2005)

A Figura 2 mostra a diversidade dos produtos finais que podem ser gerados a partir da matéria-prima do couro, sendo considerados neste artigo, para fins de Indicação Geográfica na modalidade de Indicação de Procedência os artefatos, de couro.

\section{Indicação Geográfica}

A Indicação Geográfica (IG) é o reconhecimento de que um produto ou serviço é proveniente de determinada área geográfica. Embora seja um conceito relativamente "novo", é possível encontrar referências desde os tempos bíblicos sobre a percepção que produtores $e$ consumidores tinham de determinadas características especiais de alguns produtos devido à sua origem (INPI, 2019a; INPI, 2019b).

De acordo com o Serviço de Apoio às Micro e Pequenas Empresas (SEBRAE), as indicações geográficas são ferramentas coletivas de valorização de produtos tradicionais vinculados a determinados territórios, tendo como principais funções, a agregação de valor ao produto e a proteção à região produtora (SEBRAE, 2017).

A abrangência de diversos produtos no mercado nacional e internacional não é apenas firmada por sua marca, mas também pela indicação verdadeira da sua origem geográfica. Tal indicação lhe atribui certa notoriedade, a qual está relacionada com o local da produção, entre outras características que lhe confira um diferencial dos demais produtos da mesma natureza que se encontram no mercado (SEBRAE, 2017).

Na Europa, o embasamento legal protege apenas vinhos, bebidas espirituosas e produtos agroalimentares, o que é distinto do Brasil, que por sua vez inclui vários produtos, tais como alimentos, calçados, mármores e até serviços (MAIORKI; DALLABRIDA, 2015). 
As Indicações Geográficas no Brasil estão regulamentadas pela Lei n. 9.279/96 (Lei da Propriedade Industrial), que conforme o artigo 176, a classifica em Indicação de Procedência e Denominação de Origem (BRASIL, 1996).

Além disso, foi instituído em parágrafo único que o Instituto Nacional da Propriedade Industrial (INPI) estabelecerá todas as condições para registro de Indicação Geográfica.

A Instrução Normativa n. 95, de 28 de dezembro de 2018, vem reafirmando o papel do INPI, e considerando a crescente importância da Indicação Geográfica para o desenvolvimento econômico e territorial. De acordo com o artigo $2^{\circ}$ da instrução normativa supracitada, tem-se que Indicação de Procedência (IP) o nome geográfico (país, cidade, região ou localidade) de seu território, que tenha se tornado conhecido como centro de extração, fabricação ou produção de determinado produto ou de determinada prestação de serviço. E a Denominação de Origem (DO) o nome geográfico (país, cidade, região ou localidade) de seu território, que designe produto ou serviço cujas qualidades e características se devam exclusivamente ou essencialmente ao meio geográfico, incluindo fatores naturais e humanos (INPI, 2018b).

Para a DO, é levada em consideração também a qualidade de produto, a qual é apresentada na Instrução Normativa, mencionada no parágrafo anterior, como, atributos tecnicamente comprováveis e mensuráveis do produto ou serviço, ou de sua cadeia produtiva ou de prestação de serviços. Vale ressaltar que o saber-fazer é considerado um fator humano, desde quando o mesmo é inserido nas diversas etapas que resultam em características únicas, as quais se distinguem da produção de outros territórios.

O INPI disponibiliza regulamentos de uso de indicações geográficas trata-se de um documento obrigatório junto ao órgão para solicitação de um pedido de IG, que consiste nas regras aprovadas pela coletividade que utilizará a IG, retratando a tipicidade do produto, valorizando as suas características principais e preservando o vínculo com a origem geográfica. Atualmente, existem 66 regulamentos de uso de indicações geográficas registradas no INPI, nacionais e estrangeiras. Um regulamento bem estruturado, e que descreva as melhores práticas da cadeia produtiva, auxilia a preservação das tradições, da coletividade e no fortalecimento da própria indicação geográfica (INPI, 2018b).

Vale ressaltar que o regulamento de uso passou a se chamar Caderno de Especificações Técnicas, conforme Instrução Normativa n. 95/2018. A IN ainda trouxe como novidade a possibilidade de realizar alteração de um registro de IG, como: a inclusão ou supressão do nome do produto ou serviço e alteração da representação gráfica/figurativa (INPI, 2018a).

Os benefícios obtidos através da Indicação geográfica são variados e envolvem muitos aspectos, pois as indicações geográficas passam uma imagem associada à qualidade, reputação e identidade dos produtos e/ou serviços. O seu registro ajuda a evitar o uso indevido por produtores instalados fora da área demarcada geograficamente e também confere maior competitividade nos mercados dentro e fora do país, melhorando a comercialização dos produtos e/ou ofertas dos serviços.

Além disso, a preservação da biodiversidade, do conhecimento e dos recursos naturais são outras vantagens apresentadas pelas indicações geográficas que traz também o desenvolvimento de territórios e regiões de forma positiva, por meio da criação de valor local.

Os benefícios citados e sua importância foram organizados no Quadro 1 a partir das informações acerca de Indicação Geográfica publicadas no infográfico em 2018. 
Quadro 1 - A importância e os benefícios obtidos através da Indicação Geográfica

\begin{tabular}{|c|c|}
\hline BENEFÍCIOS & IMPORTÂNCIA \\
\hline Agrega valor & Os produtos e/ou serviços são diferenciados dos demais. \\
\hline Preserva & $\begin{array}{l}\text { As particularidades do produto e/ou serviço e } \\
\text { o patrimônio da região especifica. }\end{array}$ \\
\hline Estimula o investimento & $\begin{array}{l}\text { Na área delimitada pela IG, com a valorização das propriedades, } \\
\text { aumento do turismo, do padrão tecnológico e da oferta de emprego. }\end{array}$ \\
\hline Fideliza o consumidor & $\begin{array}{l}\text { Com o sinal distintivo da IG, sabe que encontrará um produto } \\
\text { e/ou serviço de qualidade e características definidas. }\end{array}$ \\
\hline Melhora a comercialização & $\begin{array}{l}\text { Os produtos e/ou serviços facilitando o acesso ao mercado } \\
\text { nacional, e em alguns casos ao mercado internacional. }\end{array}$ \\
\hline Ativo coletivo & Agrega os produtores e prestadores de serviços. \\
\hline
\end{tabular}

Fonte: Adaptado do SEBRAE/MT (2018)

As indicações geográficas tornam-se objeto de políticas públicas, mas, sobretudo, um espaço das ações coletivas. Por isso, é necessária uma atuação conjunta das empresas para se tornarem competitivas no mercado. A política de conscientização de produtores e prestadores de serviços e a implementação das regras para o reconhecimento e a proteção das indicações geográficas no Brasil é fator importante para distinção dos produtos, agregação de valor e inserção em novos mercados (CUNHA, 2011). Por esse motivo, a contribuição da sociedade civil e dos setores da economia que fazem parte do objeto da Indicação Geográfica é crucial.

\section{O Município de Ipirá}

O município de Ipirá está situado no território de identidade da Bacia do Jacuípe (BA), e inicialmente, estava somado a outros 13 municípios: Baixa Grande, Capela do Alto Alegre, Gavião, Mairi, Nova Fátima, Pé de Serra, Pintadas, Quixabeira, Riachão do Jacuípe, São José do Jacuípe, Serra Preta, Várzea da Roça e Várzea do Poço. Recentemente o município de Capim Grosso passou a fazer parte do território de identidade, mantendo-se as principais características da orientação à agropecuária com cerca de $55 \%$ da população vivendo no campo (SEPLAN/ BA, 2016).

Em tamanho populacional Ipirá está em $35^{\circ}$ lugar no estado da Bahia. Inicialmente era chamada de Santana do Camisão e foi desmembrada de Feira de Santana em 1855, passando a ser chamada de Ipirá em 1931. A administração do município é de responsabilidade do prefeito Marcelo Antônio Santos Brandão (IBGE, 2019; IPIRÁ, 2019).

O nome Ipirá remonta de suas raízes indígenas, desde o século XVII, quando houve forte resistência à chegada dos Portugueses. Em tupi significa "cabeça de peixe" e se relaciona ao rio que banha a região, o Rio do Peixe. O município se localiza na microrregião homogênea e administrativa de Feira de Santana e no âmbito econômico na região do Paraguaçu e está distante da capital por 202 km (IBGE, 2019). 
A economia do município tem forte influência da pecuária, destacando-se na criação de bovinos, caprinos e ovinos, permitindo-lhe integrar o grupo de municípios com maior produção leiteira no estado da Bahia. Ipirá possui fábrica de produção de calçados instalada com geração de cerca de 1.500 empregos diretos, além de outros investimentos no setor de couro, a exemplo das fábricas de carteiras, cintos, bolsas e pastas, as quais geram em média 2.000 empregos diretos (IPIRÁ, 2019).

$\mathrm{Na}$ contramão do processo de formação de outros municípios do Nordeste do Brasil, o município de Ipirá teve a concentração do poder nas mãos dos grandes proprietários de terras, o que manteve o local em condição de subsistência. Há relatos de antigos moradores de que no século XIX praticamente todas as terras do município estavam demarcadas por proprietários oriundos das famílias tradicionais (SOUZA, 2016).

\section{Couro de Ipirá}

Historicamente, a vocação para a elaboração de artefatos de couro em Ipirá está relacionada a diversos fatores que contribuíram para o fortalecimento da economia na região baseada nesta matéria-prima, a saber: o processo de curtimento do couro era beneficiado pela proximidade do rio do Peixe, não havia intermediação para aquisição da pele, havia facilidade de comercialização dos produtos com os coronéis, jagunços e vaqueiros, a região contava com variedade de plantas utilizadas no curtimento do couro. Todo o ciclo de produção, desde a extração da matéria-prima era realizado em Ipirá e comercializado na feira livre da cidade e, assim, ultrapassaram os limites locais com destaque para comercialização em outras feiras do Nordeste brasileiro (SOUZA, 2016).

As indicações geográficas são instrumentos de visibilidade para produtos que tem assegurada a sua qualidade ligada à origem geográfica. Tais produtos originários representam relações técnicas, sociais e econômicas, recursos locais, tradições e o saber-fazer regional e ao longo do tempo os integrantes da cadeia produtiva vão conferindo ao local a construção de uma identidade relacionada à qualidade específica da produção local, a qual não se atribui a uma pessoa ou empresa, mas ao território (BELLETTI; MARESCOTTI; TOUZARD, 2015).

É nesse contexto que se observa a potencialidade do couro de Ipirá como produto de qualidade regional particular, ligado ao conhecimento específico local, uma vez que reúne os aspectos apresentados por Belletti, Marescotti e Touzard (2015). Souza (2016) destaca a forte tradição do município à pecuária desde o seu surgimento, em que eram realizadas de forma artesanal atividades relacionadas à produção de artefatos de couro de boi e de bode e que, até hoje, o couro tem representatividade para a economia da região, incluindo seu entorno. Destaque-se que a afirmação da identidade territorial tem nascedouro na produção customizada e artesanal de artefatos de couro as margens do rio do Peixe. A produção se voltava, especialmente, para artigos de montaria, conforme relatos de produtores locais.

No território de identidade da Bacia do Jacuípe, Ipirá se destaca por concentrar aproximadamente metade das 49 indústrias distribuídas na região, cabendo o registro de que $60 \%$ da produção está concentrada no segmento de vestuários e artefatos em couro. O município, também, possui a maior concentração de estabelecimentos de agricultura familiar da Bacia do Jacuípe (SEPLAN/BA, 2016). 
Em que pese as evidências da importância da produção de couro e seus artefatos para a economia de Ipirá, o segmento conta com pouco incentivo governamental, o que confere à atividade um caráter informal, sem o uso de técnicas no processo produtivo, além inexpressiva capacidade de organização coletiva e outros fatores associados à informalidade, o que tem resultado no declínio dos curtumes (SOUZA, 2016). Nesse particular, observa-se uma contradição quando se aprecia a forte vocação do município para a produção da matéria-prima do couro e seus artefatos.

Em meio a essas limitações do segmento no contexto local, é possível vislumbrar a construção coletiva de potencialidades, de modo a reunir os requisitos para o estabelecimento de uma Indicação Geográfica. Isso através da organização coletiva, produção com padrões claros de qualidade, além de qualificação dos produtores para uso de técnicas mais adequadas à manutenção da saúde do trabalhador, restabelecimento de curtumes com possibilidades de gestão através da organização em associações ou cooperativas e participação das políticas públicas, conforme possibilidades apresentadas no item 4 deste artigo advindas da Indicação Geográfica.

Para além de imputar, também, apenas aos governos a responsabilidade pela elaboração, aplicação e efetividade das políticas públicas, o que se propõe é uma participação coletiva em que produtores, empresários e todos os envolvidos na economia local contribuam para o estabelecimento e efetividade da Indicação Geográfica, com benefícios que vão desde o estabelecimento de padrão de qualidade, maior visibilidade ao produto, geração de emprego e renda até a consolidação da região como polo para o turismo (MAIORKI; DALLABRIDA, 2015).

Contudo, ressalta-se um papel ainda maior do Estado nesse processo de fortalecimento regional através do registro de uma Indicação Geográfica quando se considera a IG como fornecedora de bens públicos, uma vez que é formada por diversos elementos que constituem o patrimônio do território, "[...] isso exige a combinação certa de iniciativas públicas e privadas, deixando espaço para a gestão coletiva" (BELLETTI; MARESCOTTI; TOUZARD, 2015, p. 55).

Os principais curtumes fornecedores do couro como matéria-prima para as indústrias de Ipirá são de Franca e Jaú/SP e Novo Hamburgo/RS, devido à melhor qualidade atribuída pelos produtores locais advinda da utilização de técnicas de melhoramento do produto final. Entretanto, há limitações relacionadas com questões logísticas que implicam em maior tempo de transporte para o fornecimento do insumo, valor do frete, refletindo no preço do produto final. Nesse sentido, quando se compara o couro produzido em Juazeiro e Alagoinhas/BA e Petrolina/PE com o produzido nas regiões Sul e Sudeste do Brasil observa-se qualidade inferior (SOUZA, 2016).

Nesse particular, observa-se a importância de políticas públicas voltadas à manutenção e restabelecimento de curtumes da região de Ipirá e do estado da Bahia. Soma-se a isso a qualificação da mão de obra e ao uso de técnicas mais adequadas para produção de couro de qualidade como matéria-prima para produção dos artefatos tende a fortalecer a cadeia produtiva, sendo benéfica aos atores envolvidos desde o início do processo produtivo.

Entende-se que a produção dos artefatos de couro constitui uma possibilidade de afirmação produtiva no cenário futuro no município de Ipirá, haja vista ser uma atividade crescente e com mercado cativo. De acordo com produtores locais, são cerca de 150 microempresas de artefatos em couro produzindo artigos que são comercializados no mercado de cidades de todas as regiões brasileiras (SOUZA, 2016, p. 94). 
O estudo desenvolvido por Souza (2016) revela, ainda, que o município de Ipirá é carente de organização coletiva e estímulo à produção para agregação de valor à mercadoria. Esse é mais um entrave a ser superado para o aproveitamento da potencialidade da região no saber-fazer dos artigos de couro e estimular produtores e as novas gerações a continuarem o legado. Tal legado reúne tradição e qualidade peculiar na produção dos artigos em couro e que tem capacidade de gerar desenvolvimento econômico e social mediante organização administrativa, através das cooperativas, e incentivo governamental nas diversas esferas de poder.

Destaque-se que o município conta com a entidade representativa Associação Ipirá Couro, com registro de iniciativas para instalação de Galpão Industrial para instalação de pequenas fábricas de artefatos de couro e revitalização da Feira do Couro (CABORONGA NOTÍCIAS, 2018).

A estruturação das relações da cadeia produtiva dos artefatos de couro em Ipirá tem suas justificativas históricas, resultando em produtos que possuem particularidades e singularidades, imprimindo marcas fiéis de um saber-fazer realizado por grupos de pessoas que carregam o sentimento incondicional de produzir e o desejo de progredir socialmente através do reconhecimento das suas habilidades manuais e intelectuais, bem como ganhar dinheiro (SOUZA, 2016, p. 103).

Como iniciativa de fortalecimento e incentivo à produção local, em 2018 foi inaugurada a Fábrica Escola do Couro, que funciona no Centro Territorial de Educação Profissional (CETEP) da Bacia do Jacuípe. Essa escola tem foco no artesanato tradicional para dotar o mercado local de profissionais qualificados para atuarem nas fábricas de bolsas e calçados instaladas na região ou na produção independente (SEPLAN/BA, 2018).

Toda essa construção histórica e identitária deve ser potencializada para que a região crie condições organizadas para o pedido de registro de uma Indicação Geográfica. Essa estruturação local gera fortalecimento da cadeia produtiva, pois passa a reunir atributos favoráveis à valorização do produto, maior envolvimento dos produtores e de todos os agentes impactados. Como exemplo dos resultados dessa organização, visando superar os diversos desafios inerentes à decisão de registro de uma IG e criar um ambiente de governança, tem-se o exemplo do Fórum Origem Capixaba, o Quadro 2 faz essa apresentação.

Esse Colegiado, criado em 2010, foi resultado da articulação de diversos órgãos governamentais e entidades da sociedade civil para o desenvolvimento de estratégias de apoio e alavancagem às indicações geográficas e marcas coletivas no estado do Espírito Santo, auxiliando na organização, branding $^{1}$, turismo, gastronomia, promoção, adequação à legislação e fomento.

Quadro 2 - Estratégias de valorização do produto a partir da origem e qualidade

\begin{tabular}{|c|c|}
\hline \multirow{4}{*}{ Desafios } & $\begin{array}{c}\text { Empoderar as entidades responsáveis estruturando a inteligência comercial } \\
\text { da IG a fim de que criem estruturas de gestão e controle que sejam } \\
\text { eficientes e condizentes com a sua realidade, alavancando o território. }\end{array}$ \\
\hline & $\begin{array}{l}\text { Engajar todos os stakeholders e comunidade para pensarem juntos a } \\
\text { origem como forma de desenvolvimento e valorização regional. }\end{array}$ \\
\hline & $\begin{array}{l}\text { Transformar a visão dos produtores a fim de que possam utilizar } \\
\text { a IG como forma de agregar valor e possibilidade de gerar } \\
\text { maior facilidade para a comercialização dos produtos. }\end{array}$ \\
\hline & $\begin{array}{c}\text { Pesquisar as características (vínculo do produto ao meio) } \\
\text { quando se trata de Denominação de Origem. }\end{array}$ \\
\hline
\end{tabular}




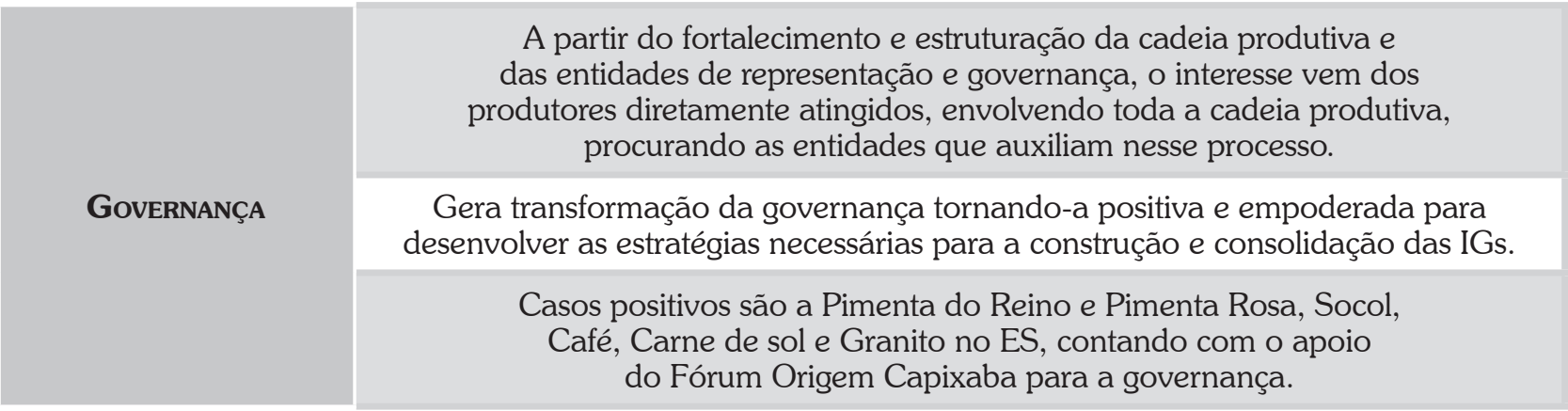

Fonte: Adaptado do SEBRAE/ES (2018)

A Bahia, também, conta com o Fórum Baiano de Indicações Geográficas, um colegiado com participação de representantes de entidades públicas e privadas, com primeira reunião em 2012 , e tem como objetivo principal promover as indicações coletivas e marcas coletivas no estado da Bahia, além de ter como objetivos específicos propor, apoiar e acompanhar ações para identificação e análise de potencialidades; fomento de ações na conquista de novos sinais distintivos; políticas públicas para ampliar a competitividade com envolvimento de toda a cadeia produtiva.

Observa-se como um desafio a interlocução entre entidades que possam fomentar a regiões com potenciais para IGs, como Ipirá, e organismos locais, como associações, produtores e poder público para discutir, propor e executar ações em direção ao registro de IG para o desenvolvimento local.

\section{Considerações Finais}

A produção de artefatos de couro de Ipirá tem um grande potencial para Indicação Geográfica na modalidade de Indicação de Procedência (IP). O nome geográfico do município de Ipirá está diretamente relacionado ao couro trabalhado na região, conferindo à localidade notoriedade na fabricação de artefatos de couro. No território de identidade da Bacia do Jacuípe, Ipirá se destaca por concentrar a maior produção de artefatos de couro.

O saber-fazer da região é um atrativo para o estabelecimento de fábricas de produção de calçados e artefatos, uma vez que tem como principal ativo o conhecimento popular adquirido desde o seu processo de colonização, em que a principal atividade era agropecuária, onde os primeiros exploradores eram grandes proprietários de terras e se voltavam, principalmente, para o plantio e criação de gado.

O acabamento dos produtos, em especial artesanalmente, diferencia os artefatos de couro de Ipirá e lhes conferem originalidade, muito vinculada aos fatores humanos. O segmento do couro na região tem a representação formal da Associação Ipirá Couro, entretanto, fontes pesquisadas revelaram a necessidade de maior capacidade de organização.

Assim, compreende-se que é imprescindível a formação de estruturas de governança, as quais devem não apenas representar a coletividade de produtores e outros atores da cadeia produtiva, mas permitir a participação e interlocução de diversos agentes como entidades de fomento, universidades, poder público e privado. A estrutura de governança deverá abrir espaço para discussões com a comunidade, capacitação da cadeia produtiva, consultoria e apoio 
jurídico, qualificação para uso de marcas, utilização de técnicas de marketing, incluindo digital, exploração de novos mercados e outras ações que visem fortalecer o Arranjo Produtivo Local.

A Indicação de Procedência para os artefatos de couro de Ipirá ultrapassa questões econômicas, em que pese esta ser essencial para a melhoria das condições da população, que vive em maior número no campo. Mas, atribui à localidade o desenvolvimento regional, também, pelo fortalecimento dos produtores, reconhecimento pela tradição na qualidade dos produtos, estimula a aprendizagem de gerações atuais e permite maior autonomia dos envolvidos para gerenciar a cadeia de valor, considerando um sistema organizado e com claros padrões de qualidade e técnicas para o processo produtivo.

\section{Referências}

ABDI - AGÊNCIA BRASILEIRA DE DESENVOLVIMENTO INDUSTRIAL. Relatório de

acompanhamento setorial: indústria do couro. 2011. Disponível em: http://www.eco.unicamp.br/ Neit/images/stories/arquivos/Relatorios_NEIT/Industria-de-Couro-marco-de-2011.pdf. Acesso em: 21 mar. 2019.

BELLETTI, Giovanni; MARESCOTTI, Andrea; TOUZARD, Jean-Marc. Geographical Indications, Public Goods, and Sustainable Development: The Roles of Actors' Strategies and Public Policies. In: WORLD DEVELOPMENT, Volume 98, October 2017, Pages 45-57. Disponível em: https:/www.sciencedirect.com/science/article/abs/pii/S0305750X15001138. Acesso em: 19 mar. 2019.

BRASIL. Lei n. 9.279, de 14 de maio de 1996 (Código de Propriedade Industrial). Regula direitos e obrigações relativos à propriedade industrial. 1996. Disponível em: http://www.planalto. gov.br/ccivil_03/leis/L9279.htm. Acesso em: 4 abr. 2019.

CABORONGA NOTÍCIAS. Associação Ipirá Couro se reúne hoje para discutir a criação do Galpão Industrial e Feira do Couro. 2018. Disponível em: https://caboronganoticias.com.br/ associacao-ipira-couro-se-reune-hoje-para-discutir-criacao-de-galpao-industrial-e-feira-do-couro/. Acesso em: 6 abr. 2019.

CUNHA, Camila Biral Vieira da. Indicações Geográficas: regulamentação nacional e compromissos internacionais. 2011. Dissertação (Mestrado em Direito) - Faculdade de Direito, Universidade de São Paulo, São Paulo, 2011. Disponível em: http://www.teses.usp.br/teses/ disponiveis/2/2135/tde-03072012-132746/pt-br.php. Acesso em: $1^{\circ}$ abr. 2019.

EMBRAPA - EMPRESA BRASILEIRA DE PESQUISA AGROPECUÁRIA. Cadeia produtiva do couro bovino: oportunidades e desafios. 2005. Disponível: https://www.infoteca.cnptia.embrapa. br/infoteca/bitstream/doc/326317/1/Cadeiaprodutivadocouro2.pdf. Acesso em: 9 abr. 2019.

IBGE - INSTITUTO BRASILEIRO DE GEOGRAFIA E ESTATÍSTICA. Cidades. 2019. Disponível em: https://cidades.ibge.gov.br/brasil/ba/ipira/panorama. Acesso em: 21 mar. 2019.

INPI - INSTITUTO NACIONAL DA PROPRIEDADE INDUSTRIAL. 2019. Guia básico de indicação geográfica. 20 mar. 2019a. Disponível em: http://www.inpi.gov.br/menu-servicos/ indicacao-geografica. Acesso em: 21 mar. 2019.

INPI - INSTITUTO NACIONAL DA PROPRIEDADE INDUSTRIAL. 2018. Instrução Normativa, $n$. 95, de 28 de dezembro de 2018a. Disponível em: http://www.inpi.gov.br/menu-servicos/indicacaogeografica/arquivos/IN952018.pdf. Acesso em: $1^{\circ}$ abr. 2019. 


\section{INPI - INSTITUTO NACIONAL DA PROPRIEDADE INDUSTRIAL. INPI disponibiliza}

regulamentos de uso de indicações geográficas. 2018b. Disponível em: http://www.inpi.gov.br/ noticias/inpi-disponibiliza-regulamentos-de-uso-de-indicacoes-geograficas. Acesso em: 01 abr. 2019.

\section{INPI - INSTITUTO NACIONAL DA PROPRIEDADE INDUSTRIAL. Novas normas para}

Indicações Geográficas entram em vigor. 2019b. Disponível em: http://www.inpi.gov.br/noticias/ novas-normas-para-indicacoes-geograficas-entram-em-vigor. Acesso em: 30 set. 2019.

IPIRÁ. (Prefeitura Municipal). [2019]. Disponível em: https://ipira.ba.gov.br/. Acesso em: 19 mar. 2019.

MAIORKI, G. J.; DALLABRIDA, V. R. A indicação geográfica de produtos: um estudo sobre sua contribuição econômica no desenvolvimento territorial. Interações, Campo Grande, [S.1.], v. 16, n. 1, p. 13-25, 2015. Disponível em: http://www.scielo.br/pdf/inter/v16n1/1518-7012-inter-16-01-0013. pdf. Acesso em: 6 mar. 2019.

NEILSON, Jeffrey; WRIGHT, Josephine; AKLIMAWATI, Lya. Geographical indications and value capture in the Indonesia coffee sector. Journal of Rural Studies, [S.1.], v. 59, April 2018, p. 35-48. Disponível em: https://www.sciencedirect.com/science/article/pii/S0743016717304588. Acesso em: 6 abr. 2019.

PIRES, Silvio R. I. Gestão da cadeia de suprimentos (Supply Chain Management): conceitos, estratégias, práticas e casos. 3. ed. São Paulo: Atlas, 2016.

\section{SECRETARIA DE EDUCAÇÃO DO ESTADO DA BAHIA. Governo da Bahia inaugura Fábrica}

Escola do Couro, em Ipirá. 2018. Disponível em: http://www.educacao.ba.gov.br/noticias/governoda-bahia-inaugura-fabrica-escola-do-couro-em-ipira. Acesso em: 6 abr. 2019.

SEPLAN/BA - SECRETARIA DO PLANEJAMENTO DO ESTADO DA BAHIA. Política Territorial. 2016. Disponível em: http://www.seplan.ba.gov.br/arquivos/File/politica-territorial/PUBLICACOES TERRITORIAIS/Planos-Territoriais-de-Desenvolvimento-Sustentavel-PTDS/2018/Proposta_FINAL_ do_PTDSS_Versao_140817.pdf. Acesso em: 1ªbr. 2019.

\section{SEBRAE/BA - SERVIÇO BRASILEIRO DE APOIO ÀS MICRO E PEQUENAS EMPRESAS. Estudo}

de Mercado Indústria: couro e calçados. 2017. Disponível em: https://m.sebrae.com.br/Sebrae/ Portal\%20Sebrae/UFs/BA/Anexos/Couro\%20e\%20cal\%C3\%A7ados\%20na\%20Bahia.pdf. Acesso em: 21 mar. 2019.

\section{SEBRAE - SERVIÇO BRASILEIRO DE APOIO ÀS MICRO E PEQUENAS EMPRESAS. O que é} indicação geográfica. 2017. Disponível em: http://www.sebrae.com.br/sites/PortalSebrae/artigos/ entenda-o-conceito-de-indicacao-geografica,5a8e438af1c92410VgnVCM100000b272010aRCRD. Acesso em: 6 mar. 2019.

SEBRAE/MT - SERVIÇO BRASILEIRO DE APOIO ÀS MICRO E PEQUENAS EMPRESAS. O que é indicação geográfica: Infográfico de mercado. 2018. Disponível em: http://www.sebrae.com.br/ Sebrae/Portal\%20Sebrae/UFs/MT/BIS/10-indicacao-geografica.pdf. Acesso em: 6 mar. 2019.

SEBRAE/ES - SERVIÇO BRASILEIRO DE APOIO ÀS MICRO E PEQUENAS EMPRESAS. Painel de Estratégias de valorização de produtos a partir da origem e da qualidade (SEBRAE/ ES) do III Seminário Internacional de Indicações Geográficas e Marcas Coletivas. 2018. Disponível em: https://datasebrae.com.br/wp-content/uploads/2018/08/Sebrae-ES.pdf. Acesso em: 16 mar. 2019. 
SEI - SUPERINTENDÊNCIA DE ESTUDOS ECONÔMICOS E SOCIAIS DA BAHIA. Territórios de Identidade: Mapas Temáticos. 2013. Disponível em: http://www.sei.ba.gov.br/images/informacoes por/territorio/indicadores_tematicos/pdf/TI_PARTICIPACAO_PIB_4V0M_2013_SEI_29112016.pdf. Acesso em: 6 abr. 2019.

SOUZA, Wesley Cerqueira. A indicação geográfica dos artefatos de couro em Ipirá/Bahia: instrumento possível de desenvolvimento territorial. 2016. Dissertação (Mestrado em Geografia) Universidade Federal da Bahia, Salvador, 2016. Disponível em: https://repositorio.ufba.br/ri/handle/ ri/20997. Acesso em: 6 mar. 2019.

VIEIRA, A. C. P. et al. A Indicação Geográfica como instrumento para o desenvolvimento de uma região: caso indicação de procedência do "Vales da Uva Goethe" - SC. PIDCC, Aracaju, ano III, edição n. 5, p. 407-425, fev. 2014. Disponível em: http://pidcc.com.br/artigos/052014/17052014.pdf. Acesso em: 4 abr. 2019.

\section{Sobre os Autores}

\section{Bartolomeu das Neves Marques}

E-mail: bartolomeumarques@yahoo.com.br

Mestrando em Propriedade Intelectual e Transferência de Tecnologia para Inovação (PROFNIT/IFBA).

Endereço profissional: PROFNIT/IFBA, Rua Emídio dos Santos, s/n, Barbalho, Salvador, BA. CEP: 40301-015.

\section{Camila Santos Bulcão}

E-mail: camila_bulcao@hotmail.com

Aluna Especial do Mestrado em Propriedade Intelectual e Transferência de Tecnologia para Inovação (PROFNIT/ IFBA).

Endereço profissional: PROFNIT/IFBA, Rua Emídio dos Santos, s/n, Barbalho, Salvador, BA. CEP: 40301-015.

\section{Ângela Maria Ferreira Lima}

E-mail: angela.lima@gmail.com

Doutorado em Energia e Ambiente (UFBA).

Endereço profissional: PROFNIT/IFBA, Rua Emídio dos Santos, s/n, Barbalho, Salvador, BA. CEP: 40301-015.

\section{Jerisnaldo Matos Lopes}

E-mail: jerislopes@hotmail.com

Doutorado em Desenvolvimento Regional e Urbano (UNIFACS).

Endereço profissional: PROFNIT/IFBA, Rua Emídio dos Santos, s/n, Barbalho, Salvador, BA. CEP: 40301-015.

\section{Marcelo Santana Silva}

E-mail: profmarceloifba@gmail.com

Pós-Doutorado em Engenharia Industrial (PEI/UFBA).

Endereço profissional: PROFNIT/IFBA, Rua Emídio dos Santos, s/n, Barbalho, Salvador, BA. CEP: 40301-015. 